\title{
Protective effects of pomegranate (Punica granatum) juice on testes against carbon tetrachloride intoxication in rats
}

\author{
Ebtesam M Al-Olayan ${ }^{1}$, Manal F El-Khadragy ${ }^{1,2}$, Dina M Metwally ${ }^{1,3}$ and Ahmed E Abdel Moneim², ${ }^{*}$
}

\begin{abstract}
Background: Pomegranate fruit has been extensively used as a natural medicine in many cultures. The present study was aimed at evaluating the protective effects of pomegranate (Punica granatum) juice against carbon tetrachloride $\left(\mathrm{CCl}_{4}\right)$-induced oxidative stress and testes injury in adult Wistar rats.

Methods: Twenty eight Wistar albino male rats were divided equally into 4 groups for the assessment of protective potential of pomegranate juice. Rats of group I (control) received only vehicles and had free access to food and water. Rats of groups II and IV were treated with $\mathrm{CCl}_{4}(2 \mathrm{ml} / \mathrm{kg} \mathrm{bwt})$ via the intraperitoneal route once a week for ten weeks. The pomegranate juice was supplemented via drinking water 2 weeks before and concurrent with $\mathrm{CCl}_{4}$ treatment to group IV. Group III was supplemented with pomegranate juice for twelve weeks. The protective effects of pomegranate on serum sex hormones, oxidative markers, activities of antioxidant enzymes and histopathology of testes were determined in $\mathrm{CCl}_{4}$-induced reproductive toxicity in rats.
\end{abstract}

Results: Pomegranate juice showed significant elevation in testosterone, luteinizing hormone (LH) and follicle stimulating hormone (FSH) those depleted by the injection of $\mathrm{CCl}_{4}$. Activity levels of endogenous testesticular antioxidant enzymes; superoxide dismutase (SOD), catalase (CAT), glutathione peroxidase (GPx), glutathione-S-transferase (GST) and glutathione reductase (GR) and glutathione (GSH) contents were increased while lipid peroxidation (LPO) and nitric oxide (NO) were decreased with pomegranate juice. Moreover, degeneration of germ and Leydig cells along with deformities in spermatogenesis induced after $\mathrm{CCl}_{4}$ injections were restored with the treatment of pomegranate juice.

Conclusion: The results clearly demonstrated that pomegranate juice augments the antioxidant defense mechanism against carbon tetrachloride-induced reproductive toxicity and provides evidence that it may have a therapeutic role in free radical mediated diseases.

Keywords: Punica granatum, Carbon tetrachloride, Oxidative stress, Testes, Rats

\section{Background}

Male sexual dysfunction composed of several problems associated with sperm concentration, motility and hormonal imbalance e.g., low testosterone level, which are caused by alcoholism, drug abuse, aging and cigarette smoking, anti depressant drugs and exposure of toxic chemicals $[1,2]$. Furthermore, an increase in oxidative damage to sperm membranes, proteins and DNA is

\footnotetext{
* Correspondence: aest1977@helwan.edu.eg

${ }^{2} Z$ Zoology \& Entomology Department, Faculty of Science, Helwan University, Cairo, Egypt

${ }^{4}$ Biochemistry and Molecular Biology Department, Asturias Institute of Biotechnology, University of Oviedo, 33006 Oviedo, Spain

Full list of author information is available at the end of the article
}

associated with alterations in signal transduction mechanisms that affect fertility [3].

Carbon tetrachloride $\left(\mathrm{CCl}_{4}\right)$, an industrial solvent, is an extensively used xenobiotic to induce chemical liver injury. $\mathrm{CCl}_{4}$ is metabolized by hepatic microsomal cytochrome P450 to trichloromethyl free radical. Trichloromethyl can react with sulfhydryl groups (glutathione and protein thiols) and antioxidant enzymes such as catalase and superoxide dismutase. Over production of trichloromethyl free radicals initiate a membrane lipid peroxidation, eventually leading to various pathological changes [4]. Studies using antioxidants indicate the role 
of oxidative stress in $\mathrm{CCl}_{4}$-induced testes injury [5]. Furthermore, some studies have revealed that natural products, containing antioxidant, protect the testes against lipid peroxidation and impairment in antioxidant status induced by $\mathrm{CCl}_{4}[3,4]$.

Pomegranate (Punica granatum) has been acclaimed for its health benefits, this fruit has long been cultivated and consumed as a fresh fruit or in beverage form especially in the Mediterranean region. Pomegranate fruit, juice and peel possess a marked antioxidant capacity [6] with a high content in polyphenols, in particular, ellagitannins, condensed tannins and anthocyanins [7]. Some of these antioxidant molecules have been shown to be bioavailable and safe [8]. Pomegranate juice consumption increases significantly sperm quality, spermatogenic cell density, antioxidant activity and testosterone level in male rats [9]. In addition, pomegranate juice has been proposed as chemopreventive, chemotherapeutic, antiatherosclerotic and antiinflammatory [10-12] and accordingly its consumption has grown tremendously $[8,13]$. So, it would be important to confirm the antioxidant effect of pomegranate. Therefore, this study was performed in order to investigate the protective effects of pomegranate juice on $\mathrm{CCl}_{4}$-induced oxidative stress and testes injury in adult Wistar rats.

\section{Methods}

\section{Chemicals}

Carbon tetrachloride (CCl4; CAS Number 56-23-5) and Tris-HCl buffer were purchased from Sigma (St. Louis, MO, USA). Perchloric acid, thiobarbituric acid (TBA) and trichloroacetic acid (TCA) were purchased from Merck. All other chemicals and reagents used in this study were of analytical grade. Double-distilled water was used as the solvent.

\section{Animals}

Twenty four adult male Wistar albino rats weighing 200-250 g (9-10 weeks) were obtained from The Holding Company for Biological Products and Vaccines (VACSERA, Cairo, Egypt). The animals were kept in wire bottomed cages in a room under standard condition of illumination with a 12-hours light-dark cycle at $25 \pm 1^{\circ} \mathrm{C}$ for one week until the beginning of treatment. They were provided with tap water and balanced diet ad libitum.

All experimental procedures involving animals were conducted in accordance with the guidelines of the National Program for Science and Technology of Faculty of Science, King Saud University. The study protocol was approved (No. 1/3/12337) by Ethical Committee of King Saud University (KSU), Riyadh, of the joined work between College of Science (KSU) and Zoology Department (Helwan University).

\section{Plant material}

Punica granatum fruits were collected from market of East Cairo, Egypt in the months of February-March, 2012. The plant material was authenticated in Botany Department, Faculty of Science, Helwan University, Cairo-Egypt on the basis of taxonomic characters and by direct comparison with the herbarium specimens available at the herbarium of the Botany Department.

\section{Pomegranate juice preparation}

Ten $\mathrm{kg}$ of pomegranates were washed and manually peeled, without separating the seeds. Juice was obtained using a commercial blender (Braun, Germany), filtrated with a buchner funnel and immediately diluted with distilled water to volume of $1: 3$ and stored at $-20^{\circ} \mathrm{C}$ for no longer than 2 months [13].

\section{Pomegranate juice stability}

Pomegranate juice stability was assessed by measuring initial total phenolic content and evaluating the alterations after 2 and 3 days of exposure to the same conditions as the juice supplied to the animals. The total polyphenol content of the pomegranate juice was $74.8 \mu \mathrm{g}$ gallic acid equivalent $/ \mathrm{ml}$ juice, determined following the standard Folin-Ciocalteu method. The content of polyphenol was not markedly affected after long time storage.

\section{HPLC-ESI-MS analysis}

Three replicates from juice were centrifuged in an eppendorf tube ( $2 \mathrm{~min}$ at $1400 \mathrm{rpm}$ ) and filtered through a $0.45 \mu \mathrm{m}$ filter. A liquid chromatography apparatus 1290 series from Agilent Technologies, including a degasser, a binary pump delivery system, and an automatic liquid sampler, was used and coupled to Agilent Triple Quad Model 6460 mass spectrometer detectors. The HPLC column was a ZORBAX Eclipse plus C18 $(4.6 \times 150 \mathrm{~mm}$, $5 \mu \mathrm{m}$ ) from Agilent Technologies (Agilent Technologies, Palo Alto, CA, USA). Separation was carried out by acetic acid (2\%; A) and acetonitrile (B). The following multistep linear gradient was applied: 0 min, 5\% B; 2 min, 7\% B; 4 min, 9\% B; 6 min, 12\% B; 8 min, 15\% B; 9 min, 16\% B; $10 \mathrm{~min}, 17 \% \mathrm{~B} ; 11 \mathrm{~min}, 17.5 \% \mathrm{~B} ; 12 \mathrm{~min}, 18 \% \mathrm{~B} ; 14 \mathrm{~min}$, $20 \%$ B; 16 min, $28 \%$ B; 18 min, 100\% B; 22 min, 100\% B; $23 \mathrm{~min}, 5 \% \mathrm{~B}$. The initial conditions were maintained for $5 \mathrm{~min}$. The flow rate was set at $0.80 \mathrm{ml} / \mathrm{min}$ throughout the gradient. The injection volume in the HPLC system was $2.5 \mu \mathrm{l}$. The chromatograms were registered at 280 and $360 \mathrm{~nm}$. Separation was carried out at $30^{\circ} \mathrm{C}$. MS analysis was carried out using electrospray ionization (ESI) interface in negative ionization mode.

\section{Experimental protocol}

To study the protective effects of pomegranate on carbon tetrachloride mediated reproductive toxicity, 
twenty eight adult male rats were randomly allocated to four groups of seven rats of each. Group I (Con) served as control and received $300 \mu \mathrm{l}$ of saline by intraperitoneal (i.p.) injection route each week. Group II $\left(\mathrm{CCl}_{4}\right)$ received weekly i.p. injection of $2 \mathrm{ml} \mathrm{CCl}_{4} / \mathrm{kg}$ body weight (bwt) for 10 weeks as described by sohn et al. [14]. Group III (Pom) received juice supplied on dark water bottles and renewed every 2-3 days [13] and the animals of group IV (Pom + $\mathrm{CCl}_{4}$ ) received pomegranate juice as group III for 2 weeks before and concurrent with $\mathrm{CCl}_{4}$ treatment that injected intraperitoneally for 10 weeks at a dose of $2 \mathrm{ml}$ of $\mathrm{CCl}_{4}$ per $\mathrm{kg}$ bwt. After one week of the last i.p. injection of $\mathrm{CCl}_{4}$, blood samples were collected from all animals by cardiac puncture (under anaesthesia with chloroform). Right testes was promptly excised, weighed and homogenized immediately to give $50 \%(\mathrm{w} / \mathrm{v})$ homogenate in ice-cold medium containing $50 \mathrm{mM}$ Tris- $\mathrm{HCl}, \mathrm{pH}, 7.4$. The homogenate was centrifuged at $3000 \mathrm{rpm}$ for $10 \mathrm{~min}$ at $4^{\circ} \mathrm{C}$. The supernatant $(10 \%)$ was used for the various biochemical determinations.

\section{Testes index}

Relative weight of testes was calculated as left testes weight/body weight $\times 100$.

\section{Biochemical estimations \\ Oxidative stress}

Homogenates of testes were used to determine lipid peroxidation (LPO) by reaction of thiobarbituric acid (TBA) [15]. Similarly, those homogenates were used to determine nitrite/nitrate (nitric oxide; NO) [16] and glutathione [17].

\section{Enzymatic antioxidant status}

Homogenates of testes were used in determination of superoxide dismutase (SOD) [18], catalase (CAT) [19], glutathione peroxidase (GPx) [20], glutathione-S-trans ferase (GST) [21] and glutathione reductase (GR) [22].

\section{Estimation of serum testosterone, luteinizing hormone and follicle stimulating hormone}

Quantitative measurement of serum testosterone, follicle stimulating hormone (FSH) and luteinizing hormone (LH) were carried out adopting ELISA technique using kits specific for rats purchased from BioVendor (Gunma, Japan) according to the protocol provided with each kit.

\section{Histological examination}

The testes tissues were collected and immediately fixed with $10 \%$ buffered formalin, and embedded in paraffin. Sections $(4-5 \mu \mathrm{m})$ were prepared and then stained with hematoxylin and eosin dye for photomicroscopic observations.

\section{Statistical analysis}

Results were expressed as the mean \pm standard error of the mean (SEM). Data for multiple variable comparisons were analyzed by one-way analysis of variance (ANOVA). For the comparison of significance between groups, Duncan's test was used as a post hoc test according to the statistical package program (SPSS version 17.0) and figures were drawn with Origin (version 8). All $p$ values are two-tailed and $p<0.05$ was considered as significant for all statistical analysis in this study.

\section{Results}

\section{HPLC-ESI-MS results}

The phytochemical fingerprint of pomegranate juice was determined using a electrospray ionization mass spectrometry (ESI-MS). HPLC-MS technique is an important method used for identifying complex mixtures, especially the phenolics or its fraction found in the plant, either by using standard compounds (target identification) or by comparing mass spectrum obtained with literatures (tentative identification). This method is useful to avoid replication, safe time, and money used in isolation and identification of known compounds. In the current study, pomegranate juice was subjected to HPLC-ESI-MS analysis. HPLC-ESI-MS experiment allowed the identification of a total of 41 compounds. Hydrolyzable tannins were the main class of (poly)phenolics identified in pomegranate juice. A broad number of anthocyanins, non-coloured flavonoids and phenolic acids were also found. Other phytochemicals, such as lignans, were also observed. Likewise, several organic acids were detected (Figure 1).

The 41 compounds were identified by the interpretation of their fragmentation patterns obtained from the mass spectrum. Data provided by literature information was employed for the comprehensive evaluation of the juice. The retention times and mass spectrum data along with peak assignments for compounds identified using negative ionization are described in Additional file 1: Table S1. As shown in Additional file 1: Table S1, m/z 301 (-) ions from MS analysis are evidence for the presence of ellagic acid precursor and HHDP in the molecules. Ellagitannins were also detected in the pomegranate juice assessed. They were distinguished by their characteristic fragment ion spectra yielding sequential losses of galloyl (m/z 152), gallate (m/z 170). Gallotannins, composed by monomeric and dimeric galloyl moieties linked to a hexose sugar were also detected. Six compounds matching the molecular ion $\mathrm{m} / \mathrm{z} 331$ were observed and considered as gallotannins. The different flavonoids belonging to four subclasses of non-coloured flavonoids (flavan-3ols, flavonols, dihydrochalcones and flavanones) were detected. The flavan-3-ols detected was (+)-gallocatechin. Kaempferol, phlorizin and quercetin displayed flavonols, dihydrochalcones and flavanones subclasses, 


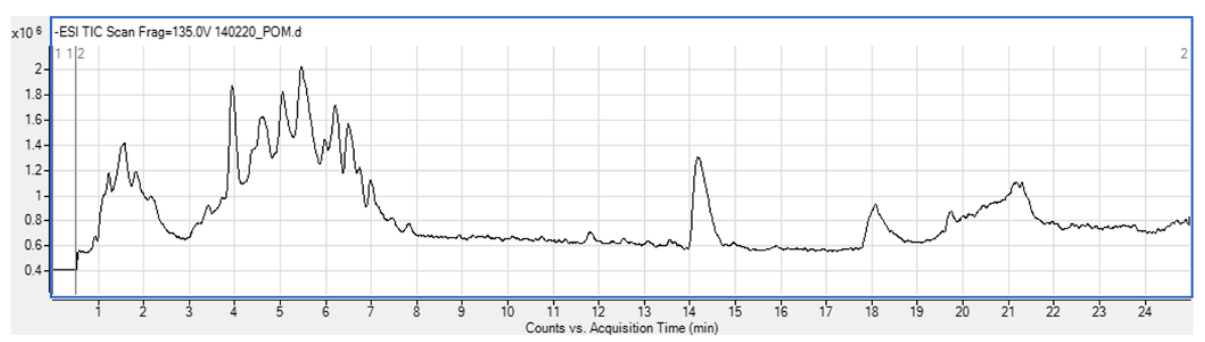

Figure 1 HPLC-ESI-MS chromatogram of $P$. granatum juice.

respectively. A total of three phenolic acid derivatives were found in pomegranate juice in this study, vanillic acid, its hexoside and syringetin-hexoside. In chromatographic analysis, organic acids were separated and identified by comparison with published data. Citric acid and its derivative have been pointed out as the main organic acids in pomegranate juices. As summarized in Additional file 1: Table S1, six anthocyanins were detected. Anthocyanins are the phenolics responsible for the red colour of pomegranate juice. The anthocyanin profile comprised cyanidin, pelargonidin, and delphinidin.

Additionally, gas chromatography-mass spectrometry (GC-MS) analysis experiment was performed. GC-MS chromatogram of the pomegranate juice showed 33 peaks indicating the presence of 33 phytochemical constituents (Additional file 2: Figure S1 and Table S2).

\section{Testes index}

The toxicity of $\mathrm{CCl}_{4}$ on testes weight and the relative testes weight were represented in Figure 2. The injection of rats with $\mathrm{CCl}_{4}$ caused a significant increase in testes weight $(1.4 \mathrm{~g} ; p<0.05)$ and relative testes weight by $74.63 \%$ comparing to the control group. Treatment with pomegranate juice erased the $\mathrm{CCl}_{4}$ toxicity and significantly improved testes weight and relative testes weight when compared with the $\mathrm{CCl}_{4}$ group which helps in reducing edema in the testes due to fluid accumulation, however, pomegranate juice failed to return the testes weight and relative testes weight ( $1 \mathrm{~g}$ and $23.88 \%$, respectively) to the control values. Supplementation of pomegranate juice on its own did not change the testes weight $(0.78 \mathrm{~g})$ and relative testes weight as compared with that in the control group.

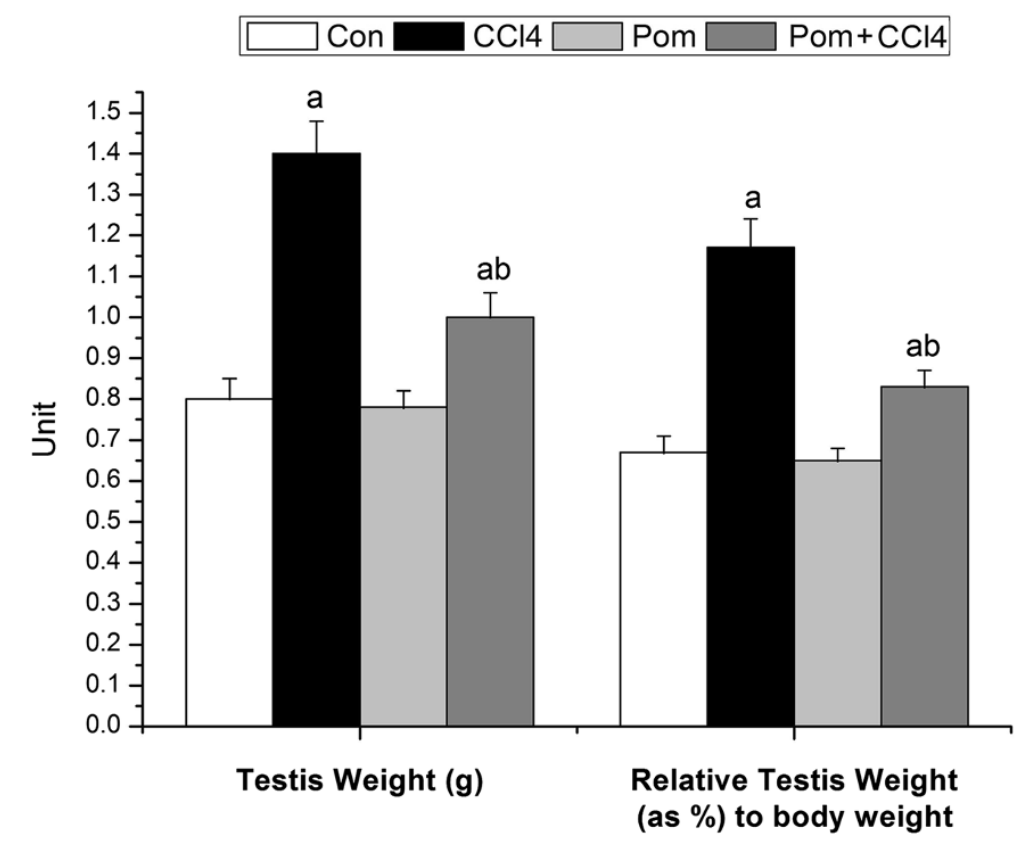

Figure 2 Effect of $P$. granatum juice on testes weight and relative testes body weight of rats treated with $\mathrm{CCl}_{4}$. Values are means $\pm \mathrm{SEM}$ $(\mathrm{n}=7)$. a: significant change at $p<0.05$ with respect to the Con group. b: significant change at $p<0.05$ with respect to the $\mathbf{C C l}_{\mathbf{4}} \mathrm{group}$. 


\section{Redox status}

The LPO level is widely used as a marker of free-radical mediated lipid peroxidation. The results of the LPO assays in the testes homogenates are shown in Figure 3. LPO level in the $\mathrm{CCl}_{4}$-treated group (65.9\%) was significantly higher than in the vehicle-control group. Supplementation of pomegranate juice significantly decreased $\mathrm{CCl}_{4}$-induced testisticular lipid peroxidation. $\mathrm{NO}$ reacts with $\mathrm{O}_{2}{ }^{--}$and leads to the formation of $\mathrm{ONOO}^{-}$(peroxynitrite), which contributes to reproductive toxicity due to its cytotoxicity properties. $\mathrm{CCl}_{4}$ injection caused a significant increase $(58.4 \% ; p<0.05)$ in NO content in testes homogenates compared to the control group. This oxidant molecule was significantly reduced (20.8\%) when animals were supplemented with pomegranate juice showing the ameliorative effects of pomegranate juice (Figure 3).

Antioxidant enzymes such as CAT, SOD, GPx, GR and GST, as well as, glutathione as a non-enzymatic antioxidant substance were estimated in the present study. There was a significant decrease in GSH in the testes homogenates of $\mathrm{CCl}_{4}$ group as compared to the control group $(-22.90 \%$ at $p<0.05)$. The supplementation of rats with pomegranate juice pre- and concurrent with $\mathrm{CCl}_{4}$ injection caused a significant increase in GSH not only when compared with $\mathrm{CCl}_{4}$ group but also with the control group (Table 1). GPx, GR and GST activities were also significantly decreased in the testisticular tissues of rats inoculated with $\mathrm{CCl}_{4}$ (Table 1), but pomegranate juice was able to significantly elevate these parameters after 10 weeks of $\mathrm{CCl}_{4}$ injection.

Carbon tetrachloride decreased the activities of SOD and CAT to approximately $-55.81 \%$ and $-29.87 \%$, respectively, compared to the control group (Figure 4). Rats supplemented with pomegranate together with $\mathrm{CCl}_{4}$ for 12 weeks experienced a significant increase in $\mathrm{SOD}$ and CAT compared to the $\mathrm{CCl}_{4}$ group (Figure 4).

\section{Hormonal fertility studies}

The mean values of the serum hormones; testosterone, luteinizing hormone and follicle stimulating hormone are shown in Figure 5. After treatment of rats with $\mathrm{CCl}_{4}$ for 10 weeks, the mean values of testosterone, $\mathrm{LH}$ and FSH were decreased as compared to the control group $(-72.1 \%,-65.4 \%$ and $-19.0 \%$, respectively). In the (Pom + $\mathrm{CCl}_{4}$ ) treated group, testosterone levels were restored to control values. Serum level of LH in this group was increased significantly as compared with the $\mathrm{CCl}_{4}$ treated group $(p<0.05)$, but it still decreased significantly compared to the control group. Mean values of $\mathrm{FSH}$ in the $\left(\mathrm{Pom}+\mathrm{CCl}_{4}\right)$ treated group did not differ from the $\mathrm{CCl}_{4}$-treated group. Statistically significant increase in the levels of testosterone, $\mathrm{LH}$ and FSH were observed in rats treated with pomegranate juice on its own as compared to the control group.

\section{Histological studies}

Among rats given daily pomegranate juice supplements alone, there were no marked changes in testicular histology relative to controls (Figure 6C). Thus normal spermatogenesis, well preserved Sertoli cells and well delineated tubular basement membrane were observed. The interstitium between tubules and Leydig cells was also intact. However, in the $\mathrm{CCl}_{4}$-treated group, differences were observed in the histology of testes, where complete swallowing of seminiferous tubules was exhibited while in other areas of the section the tubular basement membranes of seminiferous tubules were identified, but most of the germ cells were degenerated, especially the ones involving highly differentiated germ cells along with deformed sperm. The ground substance within the interstitium also partially disappeared and was replaced by fibroblast and inflammatory cells (Figure 6B). In the $\left(\right.$ Pom $\left.+\mathrm{CCl}_{4}\right)$-treated group, those toxic effects were ameliorated (Figure 6D).

\section{Lipid peroxidation}
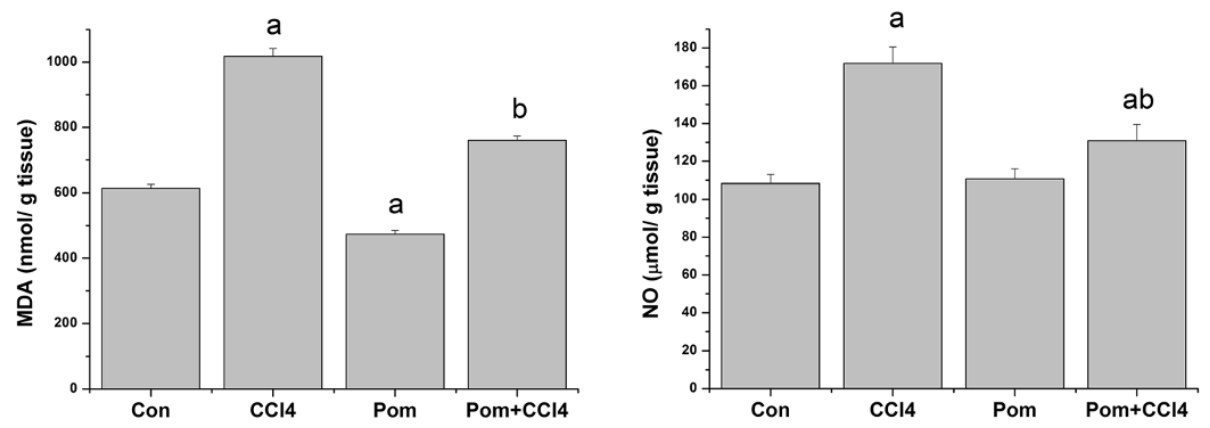

Figure 3 Effect of $P$. granatum juice on lipid peroxidation, expressed as malondialdehyde (MDA), and nitric oxide (NO) contents in testes of rats treated with $\mathrm{CCl}_{\mathbf{4}}$. Values are means $\pm \mathrm{SEM}(n=7)$. a: significant change at $p<0.05$ with respect to the Con group. b: significant change at $p<0.05$ with respect to the $\mathbf{C C l}_{\mathbf{4}}$ group. 
Table 1 Protective roles of $\boldsymbol{P}$. granatum juice on glutathione (GSH) content and glutathione-S-transferase (GST), glutathione peroxidase (GPX) and glutathione reductase (GR) activities on testes of rats treated with $\mathrm{CCl}_{4}$

\begin{tabular}{lcccc}
\hline Groups & GSH $(\mathbf{m m o l} / \mathbf{g}$ tissue $)$ & GST $(\boldsymbol{\mu m o l} / \mathbf{h} / \mathbf{g}$ tissue $)$ & GPx $(\mathbf{U} / \mathbf{g}$ tissue $)$ & GR $(\mu \mathrm{mol} / \mathbf{g}$ tissue $)$ \\
\hline Con & $18.08 \pm 0.65$ & $0.31 \pm 0.02$ & $1144.32 \pm 66.07$ & $7.23 \pm 0.39$ \\
$\mathrm{CCl}_{\mathbf{4}}$ & $13.94 \pm 1.11^{\mathrm{a}}$ & $0.12 \pm 0.01^{\mathrm{a}}$ & $736.33 \pm 39.75^{\mathrm{a}}$ & $5.22 \pm 0.38^{\mathrm{a}}$ \\
Pom & $32.72 \pm 0.93^{\mathrm{a}}$ & $0.42 \pm 0.01^{\mathrm{a}}$ & $1155.04 \pm 92.86$ & $7.51 \pm 0.34$ \\
Pom $+\mathrm{CCl}_{\mathbf{4}}$ & $22.41 \pm 0.71^{\mathrm{ab}}$ & $0.16 \pm 0.01^{\mathrm{a}}$ & $856.87 \pm 63.50^{\mathrm{a}}$ & $5.69 \pm 0.19^{\mathrm{a}}$ \\
\hline
\end{tabular}

Values are means \pm SEM $(\mathrm{n}=7)^{{ }^{a}}{ }^{\text {: }}$ significant change at $p<0.05$ with respect to the Con group, ${ }^{\text {b}}:$ significant change at $p<0.05$ with respect to $\mathbf{C C l}_{\mathbf{4}}$ group.

\section{Discussion}

Our study was focused on the protective effect of pomegranate juice against $\mathrm{CCl}_{4}$-induced reproductive toxicity in male rats. Pomegranate has a protective effect due to its active ingredients like tannins [23,24], phenolic acids [25], estrogenic flavonoids [26] and conjugated fatty acids [27], these compounds are found in substantial amounts in the peels, juice and seed oil of the pomegranate fruits [28].

Our results with the pomegranate juice agree with previous reports showing that some flavonoids from plants and fruits were potent $\mathrm{O}_{2}{ }^{-{ }^{-}}$scavengers [29]. Moreover, several studies have shown that the pharmacological effects of flavonoids are related to their antioxidant activity, which can be due to their ability to scavenge $\mathrm{OH}^{*}$ and $\mathrm{O}_{2}{ }^{\cdot-}$, to chelate metal ions and to exert a synergistic effects with other antioxidant metabolites [30-32]. Our results in conjunction with the others mentioned above, suggest that flavonoids could constitute one of the active components of $P$. granatum.

The basis of $\mathrm{CCl}_{4}$ testisticular toxicity lies in its biotransformation by the cytochrome $\mathrm{P}-450$ system giving the trichloromethyl radical $\left(\mathrm{CCl}_{3}{ }^{\circ}\right)$ which is further

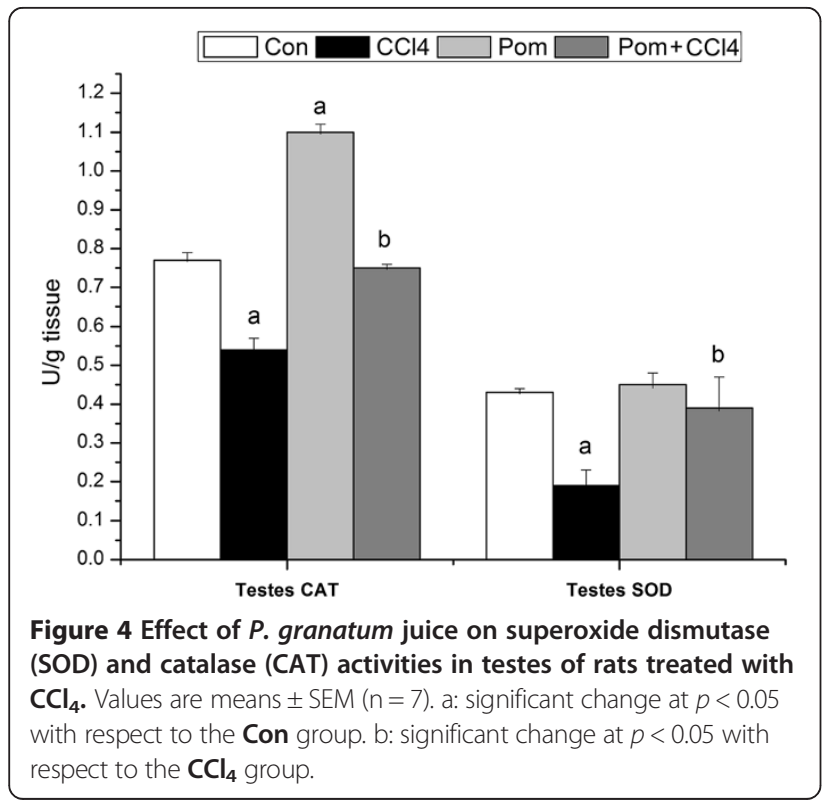

converting to the trichloromethyl peroxyl radical $\left(\mathrm{CCl}_{3} \mathrm{O}_{2}{ }^{\circ}\right)$. $\mathrm{CCl}_{4}$ metabolites react with polyunsaturated fatty acids and form covalent adducts with lipids and proteins. These events lead to lipid peroxide formation and destruction of cell membranes with the consequent testis injury [33].

The NO radicals play an important role in inducing an inflammatory response and their toxicity multiplies only when they react with $\mathrm{O}_{2}{ }^{\cdot-}$ radicals to form peroxynitrite, that damages biomolecules such as proteins, lipids and nucleic acids [34,35]. In our results, pomegranate juice was active and it may possess very potent and novel therapeutic agents for the scavenging of NO. This juice may also exert their effects on the regulation of pathological conditions caused by excessive generation of $\mathrm{NO}$ and its oxidation product-peroxynitrite.

It has been reported that SOD, CAT and GST constitute a mutually supportive defense system against ROS [36-38]. In the present study, we demonstrated that $\mathrm{CCl}_{4}$ induced a significant decrease in the activities of antioxidant enzymes namely, CAT, SOD, GPx, GR and GST. The inhibitions in antioxidant enzymes after $\mathrm{CCl}_{4}$ injection are probably due to protein inactivation by ROS. Oxidative damage often leads to the loss of specific

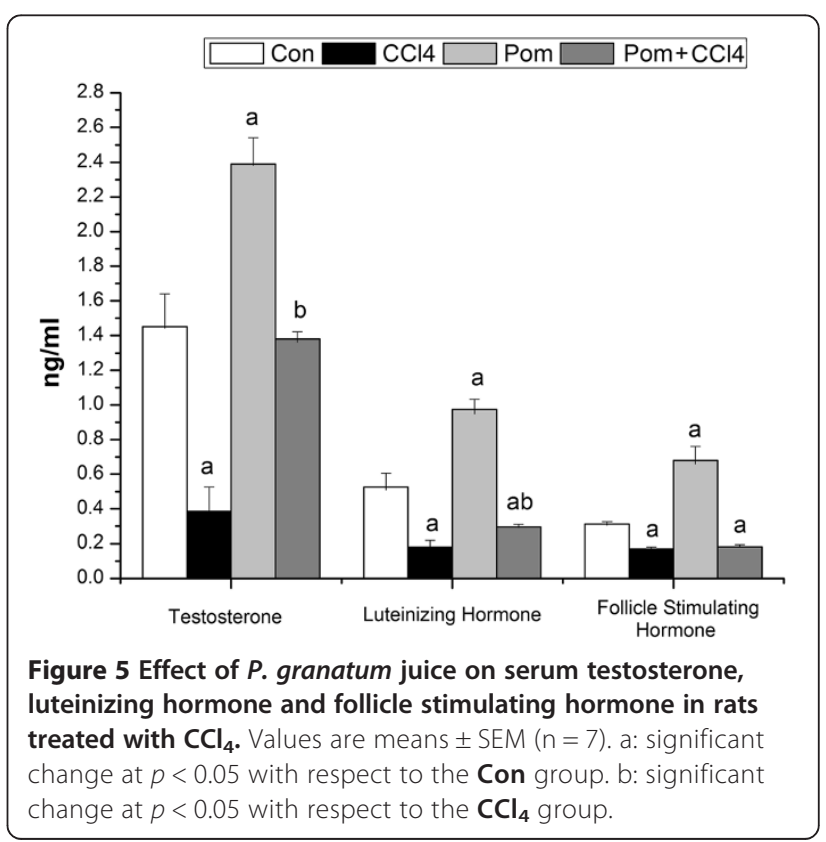




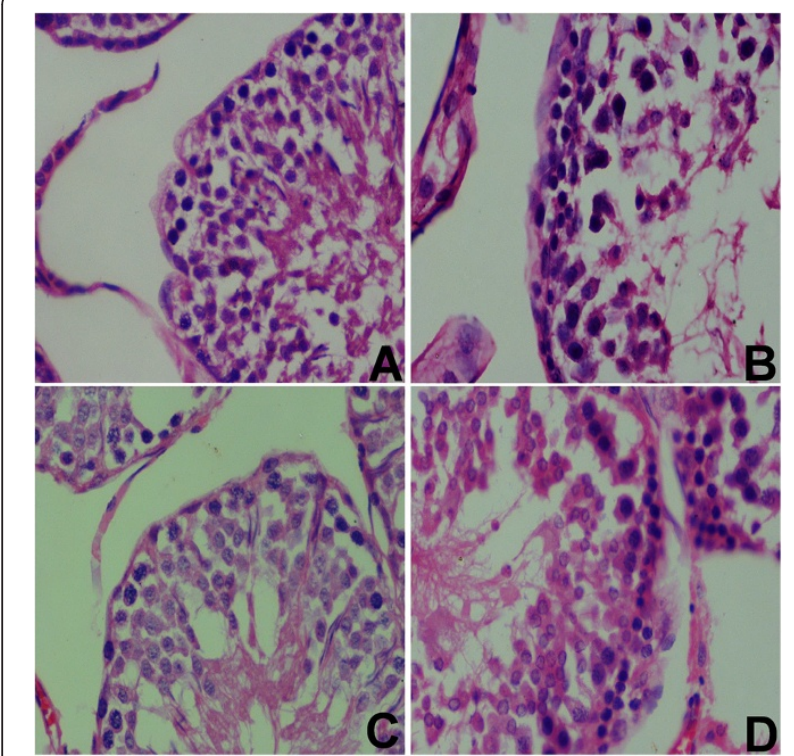

Figure 6 Histological changes in the testes of rats. (A) Control testes with normal spermatogenesis. (B) Rats treated with $\mathrm{CCl}_{4}$ with prominent inflammation, complete swallowing of seminiferous tubules and degenerated germ cells. (C) Rats supplemented with Pom. (D) Rats treated with the Pom and $\mathrm{CCl}_{4}$. Sections were stained with hematoxylin and eosin (400x).

protein function [39]. The inter-relationships between protein oxidation, protein dysfunction and diseases are still unclear, but it is known that oxidative changes in enzymes and structural proteins play a significant role in the pathophysiology of many diseases such as Parkinson's disease [40] and seizures [41].

In fact, a decrease of testisticular GST activity in $\mathrm{CCl}_{4}$ treated rodents has been reported before [42]. A decrease in GST activity during $\mathrm{CCl}_{4}$ toxicity might be due to the decreased availability of GSH during enhanced lipid peroxidation. The inhibition of SOD in testes in $\mathrm{CCl}_{4}$-treated rats may be due to the enhanced lipid peroxidation or inactivation of antioxidant enzymes. This would cause an increased accumulation of superoxide radicals, which could further stimulate lipid peroxidation. The pomegranate juice was able to partially prevent $\mathrm{CCl}_{4}$-induced decay of antioxidant enzyme activities; this preventive effect was also observed at the histological level (Figure 6). A similar scavenger role of flavonoids in mice and rats after exposure to $\mathrm{CCl}_{4}$ had been determined in liver [43].

Alterations in the spermatogenic cycle and degeneration in seminiferous tubules has been reported with $\mathrm{CCl}_{4}$ in rats [44]. In the $\mathrm{CCl}_{4}$-treated group, seminiferous tubules and germ cells were degenerated, interstitium partially disappeared and was replaced by fibroblast and inflammatory cells in some of the areas of testes. The presence of polyphenols and flavonoids in P. granatum might be involved in ameliorating the effects of $\mathrm{CCl}_{4}$ induced toxicity [45]. These constituents of pomegranate juice are thought to provide many beneficial effects against organ damages.

In the present study, $\mathrm{CCl}_{4}$ treatment decreased the serum level of testosterone, FSH and LH. Secretion of testosterone is probably impaired due to excessive oxidative stress and the degeneration of Leydig cells [46]. Metabolites of testosterone reciprocally depress FSH and LH secretion [47]. Injuries in germinal epithelial caused with $\mathrm{CCl}_{4}$ treatment can partially stimulate spermatogenesis that may occur due to less production of androgen binding proteins. The toxic effects of $\mathrm{CCl}_{4}$ might affect the suprachiasmatic hypothalamic nucleus (SCN) that may result in the failure of pituitary to secrete FSH and LH and will result in testicular dysfunction leading to infertility [48]. Treatment of rats with pomegranate juice ameliorated the toxic effects of $\mathrm{CCl}_{4}$ and the levels of testosterone, FSH and LH were increased. Pomegranate contains tannins, phenols and flavonoids which can directly or indirectly reduce oxidative damage by preventing the excessive generation of free radicals. In addition, treatment of rats with pomegranate juice alone, slightly increases the serum levels of testosterone, FSH and LH. The increase in sex hormones in the present study due to the pomegranate juice can be in part due to the ability of pomegranate to reduce stress hormones, such as cortisol, as seen by Hong et al. [49].

\section{Conclusion}

The results clearly demonstrate that pomegranate juice augments the antioxidants defense mechanism against carbon tetrachloride-induced reproductive toxicity and provides evidence that it may have a therapeutic role in free radical mediated diseases. Our results show that the protective effect of pomegranate may be due to both an increase in the activity of the antioxidant-defense system and an inhibition of lipid peroxidation and nitric oxide production.

\section{Additional files}

Additional file 1: Table S1. Identification of phytochemical compounds by HPLC-ESI-MS in pomegranate juice.

Additional file 2: Figure S1. GC-MS analysis of pomegranate juice. Table S2. Identification of phytochemical compounds by GC-MS in pomegranate juice.

\section{Abbreviations}

$\mathrm{CCl}_{4}$ : Carbon tetrachloride; ROS: Reactive oxygen species; LPO: Lipid peroxidation; NO: Nitric oxide; GSH: Glutathione; SOD: Superoxide dismutase; CAT: Catalase; GPx: Glutathione peroxidase; GST: Glutathione-S-transferase; GR: Glutathione reductase; FSH: Follicle stimulating hormone; LH: Luteinizing hormone. 


\section{Competing interests}

The authors declared that they have no competing interests.

\section{Authors' contributions}

AA made a significant contribution to conception and design of the study, acquisition and analyses of data and drafting of the manuscript. ME, DM and EA made contribution in sample collection and design. All the authors read the revised manuscript and approved.

\section{Acknowledgments}

The authors extend their appreciation to the deanship of scientific research at King Saud University for funding the work through the research group project No. RGPVPP- 074

\section{Author details}

${ }^{1}$ Zoology Department, Faculty of Science, King Saud University, Riyadh, KSA. ${ }^{2}$ Zoology \& Entomology Department, Faculty of Science, Helwan University, Cairo, Egypt. ${ }^{3}$ Parasitology Department, Faculty of Veterinary Medicine, Zagazig University, Zagazig, Egypt. ${ }^{4}$ Biochemistry and Molecular Biology Department, Asturias Institute of Biotechnology, University of Oviedo, 33006 Oviedo, Spain

Received: 25 March 2013 Accepted: 13 May 2014

Published: 22 May 2014

\section{References}

1. Khan RA: Protective effects of Launaea procumbens on rat testis damage by CCl4. Lipids Health Dis 2012, 11:103.

2. Othman MS, Nada A, Zaki HS, Abdel Moneim AE: Effect of Physalis peruviana L. on cadmium-induced testicular toxicity in rats. Biol Trace Elem Res 2014 2014:2014. doi:10.1007/s12011-014-9955-1.

3. Khan MR, Ahmed D: Protective effects of Digera muricata (L.) Mart. on testis against oxidative stress of carbon tetrachloride in rat. Food Chem Toxicol 2009, 47(6):1393-1399.

4. Cemek M, Aymelek F, Buyukokuroglu ME, Karaca T, Buyukben A, Yilmaz F: Protective potential of Royal Jelly against carbon tetrachloride inducedtoxicity and changes in the serum sialic acid levels. Food Chem Toxicol 2010, 48(10):2827-2832.

5. Al-Olayan E, El-Khadragy MF, Othman MS, Aref A, Kassab R, Abdel Moneim AE: The potential protective effect of Physalis peruviana $L$. against carbon tetrachloride-induced hepatotoxicity in rats is mediated by suppression of oxidative stress and downregulation of MMP-9 expression. Oxid Med Cell Longev 2014, 2014:Article ID 381413, 12 pages.

6. Kaur G, Jabbar Z, Athar M, Alam MS: Punica granatum (pomegranate) flower extract possesses potent antioxidant activity and abrogates Fe-NTA induced hepatotoxicity in mice. Food Chem Toxicol 2006, 44(7):984-993.

7. Seeram NP, Adams LS, Henning SM, Niu Y, Zhang Y, Nair MG, Heber D: In vitro antiproliferative, apoptotic and antioxidant activities of punicalagin, ellagic acid and a total pomegranate tannin extract are enhanced in combination with other polyphenols as found in pomegranate juice. $J$ Nutr Biochem 2005, 16(6):360-367.

8. Mertens-Talcott SU, Jilma-Stohlawetz P, Rios J, Hingorani L, Derendorf H: Absorption, metabolism, and antioxidant effects of pomegranate (Punica granatum L.) polyphenols after ingestion of a standardized extract in healthy human volunteers. J Agric Food Chem 2006, 54(23):8956-8961.

9. Turk G, Sonmez M, Aydin M, Yuce A, Gur S, Yuksel M, Aksu EH, Aksoy H: Effects of pomegranate juice consumption on sperm quality, spermatogenic cell density, antioxidant activity and testosterone level in male rats. Clin Nutr 2008, 27(2):289-296.

10. Rozenberg O, Howell A, Aviram M: Pomegranate juice sugar fraction reduces macrophage oxidative state, whereas white grape juice sugar fraction increases it. Atherosclerosis 2006, 188(1):68-76.

11. Adams LS, Seeram NP, Aggarwal BB, Takada Y, Sand D, Heber D: Pomegranate juice, total pomegranate ellagitannins, and punicalagin suppress inflammatory cell signaling in colon cancer cells. J Agric Food Chem 2006, 54(3):980-985.

12. Malik A, Afaq F, Sarfaraz S, Adhami VM, Syed DN, Mukhtar H: Pomegranate fruit juice for chemoprevention and chemotherapy of prostate cancer. Proc Natl Acad Sci U S A 2005, 102(41):14813-14818.
13. Faria A, Monteiro R, Mateus N, Azevedo I, Calhau C: Effect of pomegranate (Punica granatum) juice intake on hepatic oxidative stress. Eur J Nutr 2007, 46(5):271-278.

14. Sohn DH, Yun YP, Park KS, Veech RL, Song BJ: Post-translational reduction of cytochrome P450IIE by CCl4, its substrate. Biochem Biophys Res Commun 1991, 179(1):449-454.

15. Ohkawa $\mathrm{H}$, Ohishi $\mathrm{N}$, Yagi K: Assay for lipid peroxides in animal tissues by thiobarbituric acid reaction. Anal Biochem 1979, 95(2):351-358.

16. Green LC, Wagner DA, Glogowski J, Skipper PL, Wishnok JS, Tannenbaum SR: Analysis of nitrate, nitrite, and [15 N]nitrate in biological fluids. Anal Biochem 1982, 126(1):131-138.

17. Ellman GL: Tissue sulfhydryl groups. Arch Biochem Biophys 1959, 82(1):70-77

18. Nishikimi M, Appaji N, Yagi K: The occurrence of superoxide anion in the reaction of reduced phenazine methosulfate and molecular oxygen. Biochem Biophys Res Commun 1972, 46(2):849-854.

19. Aebi H: Catalase in vitro. Methods Enzymol 1984, 105:121-126.

20. Paglia DE, Valentine WN: Studies on the quantitative and qualitative characterization of erythrocyte glutathione peroxidase. J Lab Clin Med 1967, 70(1):158-169.

21. Habig WH, Pabst MJ, Jakoby WB: Glutathione S-transferases. The first enzymatic step in mercapturic acid formation. J Biol Chem 1974 249(22):7130-7139.

22. Factor VM, Kiss A, Woitach JT, Wirth PJ, Thorgeirsson SS: Disruption of redox homeostasis in the transforming growth factor-alpha/c-myc transgenic mouse model of accelerated hepatocarcinogenesis. J Biol Chem 1998, 273(25):15846-15853.

23. Amakura Y, Okada M, Tsuji S, Tonogai Y: High-performance liquid chromatographic determination with photodiode array detection of ellagic acid in fresh and processed fruits. J Chromatogr A 2000, 896(1-2):87-93.

24. Yehia HM, Elkhadragy MF, Abdel Moneim AE: Antimicrobial activity of pomegranate rind peel extracts. Afr J Micro Res 2011, 4(22):3664-3668.

25. Lansky EP, Harrison G, Froom P, Jiang WG: Pomegranate (Punica granatum) pure chemicals show possible synergistic inhibition of human $\mathrm{PC}-3$ prostate cancer cell invasion across Matrigel. Invest New Drugs 2005, 23(2):121-122.

26. Van Elswijk DA, Schobel UP, Lansky EP, Irth H, van der Greef J: Rapid dereplication of estrogenic compounds in pomegranate (Punica granatum) using on-line biochemical detection coupled to mass spectrometry. Phytochemistry 2004, 65(2):233-241.

27. Schubert SY, Lansky EP, Neeman I: Antioxidant and eicosanoid enzyme inhibition properties of pomegranate seed oil and fermented juice flavonoids. J Ethnopharmacol 1999, 66(1):11-17.

28. Abdel Moneim AE, El-Khadragy MF: The potential effects of pomegranate (Punica granatum) juice on carbon tetrachloride-induced nephrotoxicity in rats. J Physiol Biochem 2013, 69(3):359-370.

29. Coballase-Urrutia E, Pedraza-Chaverri J, Cardenas-Rodriguez N, Huerta-Gertrudis B, Edna Garcia-Cruz M, Ramirez-Morales A, Javier Sanchez-Gonzalez D, Maria Martinez-Martinez C, Camacho-Carranza R, Javier Espinosa-Aguirre J: Hepatoprotective effect of acetonic and methanolic extracts of Heterotheca inuloides against CCl(4)-induced toxicity in rats. Exp Toxicol Pathol 2011, 63(4):363-370.

30. Niki E, Yoshida $Y$, Saito $Y$, Noguchi N: Lipid peroxidation: mechanisms, inhibition, and biological effects. Biochem Biophys Res Commun 2005, 338 (1):668-676.

31. Manna P, Sinha M, Sil PC: Aqueous extract of Terminalia arjuna prevents carbon tetrachloride induced hepatic and renal disorders. BMC Complement Altern Med 2006, 6:33.

32. Raja S, Ahamed KF, Kumar V, Mukherjee K, Bandyopadhyay A, Mukherjee PK: Antioxidant effect of Cytisus scoparius against carbon tetrachloride treated liver injury in rats. J Ethnopharmacol 2007, 109(1):41-47.

33. Szymonik-Lesiuk S, Czechowska G, Stryjecka-Zimmer M, Slomka M, Madro A, Celinski K, Wielosz M: Catalase, superoxide dismutase, and glutathione peroxidase activities in various rat tissues after carbon tetrachloride intoxication. J Hepatobiliary Pancreat Surg 2003, 10(4):309-315.

34. Gulcin I, Oktay M, Kufrevioglu Ol, Aslan A: Determination of antioxidant activity of lichen Cetraria islandica (L) Ach. J Ethnopharmacol 2002, 79(3):325-329.

35. Gouthamchandra K, Mahmood R, Manjunatha $\mathrm{H}$ : Free radical scavenging, antioxidant enzymes and wound healing activities of leaves extracts from Clerodendrum infortunatum L. Environ Toxicol Pharmacol 2010, 30(1):11-18. 
36. Halliwell B: Biochemistry of oxidative stress. Biochem Soc Trans 2007, 35(Pt 5):1147-1150.

37. Valko M, Leibfritz D, Moncol J, Cronin MT, Mazur M, Telser J: Free radicals and antioxidants in normal physiological functions and human disease. Int J Biochem Cell Biol 2007, 39(1):44-84.

38. Seifried $\mathrm{HE}$, Anderson DE, Fisher El, Milner JA: A review of the interaction among dietary antioxidants and reactive oxygen species. J Nutr Biochem 2007, 18(9):567-579.

39. Tabatabaie T, Floyd RA: Susceptibility of glutathione peroxidase and glutathione reductase to oxidative damage and the protective effect of spin trapping agents. Arch Biochem Biophys 1994, 314(1):112-119.

40. Abdel Moneim AE: The neuroprotective effects of purslane (Portulaca oleracea) on rotenone-induced biochemical changes and apoptosis in brain of rat. CNS Neurol Disord Drug Targets 2013, 12(6):830-841.

41. Abdel Moneim AE: Citrus peel extract attenuates acute cyanide poisoning-induced seizures and oxidative stress in rats. CNS Neurol Disord Drug Targets in press.

42. Aniya Y, Anders MW: Alteration of hepatic glutathione S-transferases and release into serum after treatment with bromobenzene, carbon tetrachloride, or N-nitrosodimethylamine. Biochem Pharmacol 1985, 34(24):4239-4244.

43. Yuan LP, Chen FH, Ling L, Bo H, Chen ZW, Li F, Zhong MM, Xia LJ: Protective effects of total flavonoids of Bidens bipinnata $L$. against carbon tetrachloride-induced liver fibrosis in rats. J Pharm Pharmacol 2008, 60(10):1393-1402.

44. Horn MM, Ramos AR, Winkelmann L, Matte US, Goldani HA, Silveira TR: Seminiferous epithelium of rats with food restriction and carbon tetrachloride-induced cirrhosis. Int Braz J Urol 2006, 32(1):94-99. discussion 99.

45. Lin HM, Tseng HC, Wang CJ, Lin JJ, Lo CW, Chou FP: Hepatoprotective effects of Solanum nigrum Linn extract against CCI(4)-induced oxidative damage in rats. Chem Biol Interact 2008, 171(3):283-293.

46. Santos AM, Ferraz MR, Teixeira CV, Sampaio FJ, Da Fonte RC: Effects of undernutrition on serum and testicular testosterone levels and sexual function in adult rats. Horm Metab Res 2004, 36(1):27-33.

47. Steinberger $E$, Chowdhury M: The effects of testosterone propionate and estradiol benzoate on the vitro synthesis of FSH. Biol Reprod 1977, 16(3):403-408

48. Khan MR, Khan GN, Ahmed D: Evaluation of antioxidant and fertility effects of Digera muricata in male rats. Afr J Pharm Pharmacol 2011, 5(6):688-699.

49. Hong MY, Seeram NP, Heber D: Pomegranate polyphenols down-regulate expression of androgen-synthesizing genes in human prostate cancer cells overexpressing the androgen receptor. J Nutr Biochem 2008, 19(12):848-855.

doi:10.1186/1472-6882-14-164

Cite this article as: Al-Olayan et al:: Protective effects of pomegranate

(Punica granatum) juice on testes against carbon tetrachloride

intoxication in rats. BMC Complementary and Alternative Medicine 2014 14:164.

\section{Submit your next manuscript to BioMed Central and take full advantage of:}

- Convenient online submission

- Thorough peer review

- No space constraints or color figure charges

- Immediate publication on acceptance

- Inclusion in PubMed, CAS, Scopus and Google Scholar

- Research which is freely available for redistribution 